\title{
Effects of Health-Related Quality of Life on Suicidal Ideation and Depression among Older Korean Adults: A Cross-Sectional Study
}

\author{
Jinyoung Jang ${ }^{1,2}$, Hyun-Sung Jung ${ }^{1,3}$, Jumee Wang ${ }^{4}$, and Sukil Kim ${ }^{5} \bowtie$ \\ ${ }^{1}$ Department of Public Health, Graduate School, The Catholic University of Korea, Seoul, Republic of Korea \\ ${ }^{2}$ The Korean Association of Internal Medicine, Seoul, Republic of Korea \\ ${ }^{3}$ Indoor Environment and Noise Research Division, National Institute of Environmental Research, Incheon, Republic of Korea \\ ${ }^{4}$ The Korean Cardiac Research Foundation, Seoul, Republic of Korea \\ ${ }^{5}$ Department of Preventive Medicine, College of Medicine, The Catholic University of Korea, Seoul, Republic of Korea
}

\begin{abstract}
Objective The aim of this study was to investigate the prevalence of depression and suicidal ideation among older Korean adults and the predictors of suicidal ideation.

Methods We analyzed data from 5,604 Koreans aged 65 or older collected by the Korea National Health and Nutrition Examination Survey in 2012-2016, an annual national, cross-sectional, epidemiologic study of the Korean population. A chi-square test was used to assess differences in socio-demographic characteristics by suicidal ideation. Psychological variables, self-rated physical health, and the five dimensions of the Korean version of the EQ-5D (EuroQoL) were compared between four subgroups categorized according to the presence/absence of suicidal ideation and depression. Multiple logistic regression was used to estimate the predictive power of health-related quality of life variables, as well as physical and psychological factors regarding suicidal ideation.

Results Overall, $11.5 \%$ of the sample reported suicidal ideation, and $20.0 \%$ of the suicidal ideation group were diagnosed with depression. Respondents with suicidal ideation had significantly lower levels of health-related quality of life than those without suicidal ideation. EQ-5D self-control $(\mathrm{OR}=1.42)$, anxiety/depression $(\mathrm{OR}=2.32)$, depression $(\mathrm{OR}=2.07)$, and self-rated physical health $(\mathrm{OR}=1.36)$ were found to significantly predict suicidal ideation.

Conclusion Suicidal ideation without depression was prevalent among older Koreans. Self-control, anxiety/depression of EQ-5D, selfrated physical health, and depression predicted suicidal ideation. Interventions to screen older Koreans for early detection of suicide risk and prevention strategies should consider evaluating each EQ-5D dimension.

Psychiatry Investig 2021;18(1):31-38
\end{abstract}

Key Words Depression, Health-related quality of life, Suicidal ideation.

\section{INTRODUCTION}

\section{Suicide in Korea}

Currently, South Korea's suicide rate is the highest among Organization for Economic Cooperation and Development (OECD) countries. In 2017, Korea’s suicide rate was 24.3 cases per 100,000 population, which is about twice the OECD average. ${ }^{1}$ Of particular importance is that suicide rates per 100,000 positively relate to age: 70.0 among those aged 80 or older, 48.8

\footnotetext{
Received: May 1, 2020 Revised: July 17, 2020

Accepted: October 19, 2020

$\bowtie$ Correspondence: Sukil Kim, MD, PhD

Department of Preventive Medicine, College of Medicine, The Catholic University of Korea, 222 Banpo-daero, Seocho-gu, Seoul 06591, Republic of Korea Tel: +82-2-2258-7367, Fax: +82-2-532-6537, E-mail: sikimmd@catholic.ac.kr (c) This is an Open Access article distributed under the terms of the Creative Commons Attribution Non-Commercial License (https://creativecommons.org/licenses/by$\mathrm{nc} / 4.0$ ) which permits unrestricted non-commercial use, distribution, and reproduction in any medium, provided the original work is properly cited.
}

among those aged $70-79$, and $30.2,30.8,27.9,24.5$, and 16.4 among those aged $60-69,50-59,40-49,30-39$, and 20-29, respectively. ${ }^{2}$

\section{Risk factors of suicide}

Suicidal ideation (SI) is more strongly related to completed suicide among older persons than younger, because older persons employ methods that are more likely to be fatal, such as firearms, drowning, and suffocation..$^{3-5} \mathrm{SI}$ is a key independent predictor of completed suicide; ${ }^{6}$ preventing SI is therefore considered one of the most effective ways to prevent suicide completion, and is a key aspect of the suicide intervention process.? Previous studies have identified various factors that increased the risk of SI among older adults, including physical health, ${ }^{8-12}$ psychological health, ${ }^{13,14}$ stress/distress, ${ }^{12,15,16}$ financial concerns, ${ }^{12,17}$ social networks, satisfaction with social support, and loneliness ${ }^{18-20}$ and socio-demographic characteristics. ${ }^{21-23}$ 
Among various risk factors of SI, physical and psychological illness have been noted as significant predictors of SI in many previous studies; ${ }^{8-14}$ these factors are especially related to older adults, because their health condition might be worse than for other age groups. In addition, a policy to find high-risk suicide groups in Korea, has focused on depression among the elderly and an increase in the number of older adults living alone. ${ }^{24}$ In other words, mental problems such as depression and stress in the elderly can be expected to be closely linked to suicide. Therefore, it would be necessary to identify associations of SI with self-rated health, and mental health-related variables such as self-rated stress and depression.

\section{Depression and suicide risks}

Previous studies showed divergent results on the relationship between depression and suicide. First, Goldney ${ }^{25}$ reported that the prevention of seasonal depression has dramatically reduced suicide mortality as shown after performing a psychological autopsy on all suicide deaths in Finland. According to the report from the U.S department of Health and Human Services, about 60 percent of people who committed suicide had a mood disorder (e.g., major depression, bipolar disorder, dysthymia). ${ }^{26}$ Contrary to the aforementioned findings from previous studies, Joo et al. ${ }^{27}$ reported that depression disorder was not significantly associated with suicidal ideation, and rather than stress, difficulty concentrating and social isolation were significantly associated with suicidal ideation among 753 adults living in the U.S. Furthermore, according to another survey conducted in the U.S., two-thirds of older Korean Americans without minor or major depressive disorder (diagnosed by the Korean version of the Patient Health Questionnaire) reported SI (64.0\%), which was higher than the proportion of those with comorbid SI and depressive disorder (36\%). Overall, based on the literature review, we hypothesized that even though depression may be a risk factor, a large proportion of older adults who were not diagnosed with depression might be at suicide risk.

\section{Health-related quality of life (HRQoL)}

Previous studies found that low levels of HRQoL strongly influenced SI, particularly among older adults who had the lowest score scope on the EQ-5D by EuroQoL $(<0.7)$ and whose likelihoods of SI and SA (Suicidal Attempt) were higher than those of older adults with higher scores. ${ }^{28,29}$ Some studies on the relationship between HRQoL and suicide in Asian samples focused on older adults. ${ }^{30,31}$ Previous studies have examined how HRQoL affects SI and SA however, little is known about how the five dimensions of HRQoL associated with SI. Here, we aimed to systematically investigate the interplay of various HRQoL indicators and predictors of SI in older adults.
We hypothesized that the five HRQoL dimensions (EQ-5D) would be critical independent predictors of SI. These dimensions cover a broad range of individual-level health characteristics, such as functional ability, emotional state, and overall health measured using self-report items assessing expectations and achievements. ${ }^{32}$

The study objectives were as follows:

1) Identify the socio-demographic characteristics of older adults with and without SI.

2) Assess the proportions of older adults with and without depression in the SI group.

3) Analyze the proportions of predictors for SI among the four groups based on the presence/absence of SI and depression.

4) Investigate the strength of the associations between the hypothesized predictors and HRQoL with SI by performing a multiple logistic regression analysis.

\section{METHODS}

\section{Sample}

The data used in this study were derived from the Korea National Health and Nutrition Examination Survey (KNHANES V, VI, and VII; 2012-2016), a nationally representative crosssectional survey conducted by the Korean Centers for Disease Control and Prevention and the Ministry of Health and Welfare. This survey targeted non-institutionalized Korean individuals; respondents were selected to represent the Korean population using complex sampling with a stratified, clustered, and multistage probability design. In addition, this survey is based on a rolling sample survey method, which divides the entire country into 192 clusters and targets an average of 20 households per cluster to ensure the representativeness of the collected data. Selected participants received a notice of selection before data collection began, and written informed consent was obtained after receiving information on the survey's purpose. This study was conducted with approval from the Catholic Medical Center's Research Ethics Committee (IRB No. MIRB-20190719-001).

Of the 39,156 respondents to the KNHANES in 2012-2016, 7,807 individuals aged 65 or older were included in the initial sample. Of them, we excluded 543 individuals who did not respond to the question on SI and 491 individuals with missing data on other important variables, yielding a sample size of 6,773. Respondents with missing data on HRQoL $(n=1,169)$ were also excluded; thus, the final sample comprised 5,604 respondents (participation rate $=71.8 \%$ ) aged 65 years or older with complete data on the analysis variables. 


\section{Variables}

\section{Dependent variable: SI}

SI was assessed using the response to the following question: "Have you ever thought about committing suicide during the past 12 months?" The response options were "yes" or "no." The respondents who answered "yes" were assigned to the SI group; those who responded "no" were assigned to the no-SI group. This was the primary question to verify the suicidality of respondents. Two other related questions were asked, namely "Have you ever made a plan to commit suicide during the past 12 months?" and "Have you ever attempted to commit suicide during the past 12 months?" If respondents answered 'no' to the first question, they might respond 'no' to the rest of two questions.

\section{Risk factors and control variables}

The KNHANES assesses mental health status (regarding depression, stress/distress, and counseling used for psychological problems) and physical health (including self-reported status). Depression was diagnosed by clinicians. Stress/distress was assessed using subjective self-rating; the question, "How much stress do you feel in your daily life?" was answered on a 4-point Likert-type scale ( 1 =very high, 2 =high, $3=$ moderate, $4=$ minor). Counseling received during the past year was measured using the question, "Have you received counseling within the past year due to your psychological problems?"; the response options were "yes" or "no." Self-rated physical health status was assessed with the question, "How do you rate your physical condition?"; responses were provided on a 5-point Likert-type scale ( 1 =very good to $5=$ very poor). Data on age, gender, educational level, marital status, and financial status were collected as control variables. ${ }^{9,12}$

\section{HRQOL}

The KNHANES includes the Korean version of the EQ-5D by EuroQoL group ${ }^{33}$ to measure HRQoL. The EQ-5D is among the most widely evaluated HRQoL measures ${ }^{34}$ and comprises five dimensions: physical activity, self-control, daily activity, pain, and anxiety/depression, each rated based on three grades of severity: no problems, some problems, and severe problems. Previous studies found that the Korean version of the EQ-5D was valid and stable over time. ${ }^{35-38}$ In this study, the scores on the five EQ-5D dimensions were summed to provide an index following the recommendation of the Korean Centers for Disease Control and Prevention. ${ }^{39,40}$ This makes it possible to convert each score of the five dimensions into a single score. Details about this calculation are provided in Supplementary Material (in the online-only Data Supplement).

\section{Statistical analysis}

First, differences in socio-demographic characteristics between the SI group and NoSI group, as well as any differences in psychological health, physical health, and the five EQ-5D dimensions between the four SI/depression groups were evaluated using a chi-square test. The four subgroups were: 1) SI with depression ("SI-Depression"), 2) SI without depression (“SI-NoDepression"), 3) no SI with depression ("NoSI-Depression"), and 4) no SI with no depression ("NoSI-NoDepression"). Then, a binomial multiple logistic regression analysis was used to calculate the odds ratios (ORs) and 95\% confidence intervals (CIs) of the effects of the five EQ-5D dimensions, psychological health, and self-rated physical health on SI. SAS (ver. 9.2; SAS Institute, Inc., Cary, NC, USA) was used to perform all the statistical analyses, which employed sampling weights for nationally representative prevalence estimates.

\section{RESULTS}

\section{Socio-demographic characteristics of SI group and no-SI group}

In Table 1 , about $11.5 \%(\mathrm{n}=640)$ of the respondents reported experiencing SI, and $88.5 \%(n=4,964)$ of the respondents reported that they had not experienced SI during the past year. Twice as many women as men reported experiencing SI. More than half of both the SI group ( $n=395,61.7 \%)$ and no-SI group $(n=3,194,64.0 \%)$ were in the youngest age group (65-74 years), and the age distribution was not significantly different between the groups. Regarding education, elementary school graduate was the most common in both groups (SI: $n=483,74.6 \%$; noSI: $n=2,985,61.5 \%)$, but there were about twice as many college graduates in the no-SI group as in the SI group $(8.7 \%$ and $4.4 \%$, respectively), and this difference was significant ( $\mathrm{p}<0.0001)$. There was also a significant difference in both groups' monthly income, with almost two-thirds $(n=405,65 \%)$ of the SI group and less than half $(n=2,289,46 \%)$ of the no-SI group falling under the low monthly income category. The proportions of widowed ( $n=264,42.6 \%)$ and divorced $(n=43,7.5 \%)$ respondents in the SI group were significantly higher than in the noSI group (widowed: $n=1,432,30.7 \%$; divorced: $n=167,3.1 \%$ ). There were no differences in employment rates between the two groups (Table 1).

\section{Five dimensions of EQ-5D by group}

Table 2 shows the distribution of the EQ-5D dimension categories ["problems" (including both "some" and "severe problems") or "no problems"], EQ-5D index categories (range: $<0.70$ to 1.0), and mean index in the SI and no-SI groups with and without depression. About $20 \%(n=128)$ of the SI groups received a psychiatric diagnosis of depression, and about 5.8\% 
Table 1. Descriptive statistics of respondents with and without suicidal ideation

\begin{tabular}{|c|c|c|c|c|}
\hline Variable & $\begin{array}{c}\text { Suicidal } \\
\text { ideation } \\
(\mathrm{N}=640 \text {, } \\
11.5 \%)\end{array}$ & $\begin{array}{c}\text { No suicidal } \\
\text { ideation } \\
(\mathrm{N}=4,964 \\
88.5 \%)\end{array}$ & $\mathrm{p}$-value & $\begin{array}{c}\text { Total } \\
(\mathrm{N}=5,604)\end{array}$ \\
\hline & $\mathrm{N}(\%)$ & $\mathrm{N}(\%)$ & & \\
\hline Gender & & & $<0.0001$ & 5,604 \\
\hline Male & $190(7.9)$ & $2,202(92.1)$ & & 2,392 \\
\hline Female & $450(14.0)$ & $2,762(86.0)$ & & 3,212 \\
\hline Age group & & & $<0.0210$ & 5,604 \\
\hline $65-74$ & $394(61.7)$ & $3,194(64.0)$ & & \\
\hline $75-84$ & $243(37.7)$ & $1,768(35.9)$ & & \\
\hline$\geq 85$ & $3(0.6)$ & $2(0.06)$ & & \\
\hline Educational level & & & $<0.0001$ & 5,554 \\
\hline $\begin{array}{l}\text { Elementary } \\
\text { school }\end{array}$ & $483(74.6)$ & $2,985(61.5)$ & & \\
\hline Middle school & $72(11.0)$ & $685(13.7)$ & & \\
\hline High school & $58(10.0)$ & $813(16.1)$ & & \\
\hline College or more & $26(4.4)$ & $432(8.7)$ & & \\
\hline Monthly income & & & $<0.0001$ & 5,567 \\
\hline Low & $405(65.0)$ & $2,289(46.0)$ & & \\
\hline Middle-low & $146(21.5)$ & $1,370(27.6)$ & & \\
\hline Middle-high & $58(9.7)$ & $743(15.7)$ & & \\
\hline High & $26(3.8)$ & $530(10.7)$ & & \\
\hline Marital status & & & $<0.0001$ & 5,602 \\
\hline Married & $333(50.0)$ & $3,363(66.3)$ & & \\
\hline Widowed & $264(42.6)$ & $1,432(30.7)$ & & \\
\hline Divorced & $43(7.5)$ & $167(3.1)$ & & \\
\hline Financial status & & & 0.0152 & 5,604 \\
\hline Employed & $146(25.7)$ & $1,615(31.5)$ & & \\
\hline Unemployed & $494(74.3)$ & $3,349(68.5)$ & & \\
\hline
\end{tabular}

$(\mathrm{n}=291)$ of the no-SI groups had depression. A pattern emerged regarding EQ-5D indicators in which the highest proportion of those having problems was in the SI-Depression group, followed by the SI-NoDepression group, NoSI-Depression group, and NoSI-NoDepression group. The results regarding EQ-5D, psychological, and physical health in the NoSI-NoDepression group were considered usual for adults aged 65 and older and, since this group had neither SI nor depression, it was used as the reference group.

Within the SI group, those with depression were more likely to have HRQoL problems than those without depression, considering the results on the five EQ-5D dimensions. Interestingly, $47.6 \%$ ( $\mathrm{n}=241)$ of participants who were not diagnosed by a physician in the SI-NoDepression group reported anxiety/ depression problems on the EQ-5D. This was higher than in the NoSI-Depression group ( $\mathrm{n}=133,40.3 \%)$. In total, the proportion of participants in the SI-Depression group that reported problems was higher than that in the other three groups for all five EQ-5D dimensions. In particular, there were significant differences in anxiety/depression between the SI-Depression $(\mathrm{n}=94,70.1 \%)$ and SI-NoDepression $(\mathrm{n}=241,47.6 \%)$ groups $(\mathrm{p}<0.0001)$, and in physical activity problems between the SIDepression $(\mathrm{n}=91,72.2 \%)$ and SI-NoDepression $(\mathrm{n}=324,60.1 \%)$ groups $(\mathrm{p}<0.0001)$. Regarding the EQ-5D index, there were significant subgroup differences. The group with the highest proportion of participants with the lowest index level $(<0.7)$ was the SI-Depression group $(n=56,44.9 \%)$, followed by the SI-NoDepression group $(\mathrm{n}=162,28.8 \%)$. At the highest index level (1.0), the SI-Depression group showed the smallest proportion ( $\mathrm{n}=10,8.1 \%)$, followed by the SI-NoDepression group $(\mathrm{n}=92,17.5 \%)$ (Table 2).

\section{Stress and physical health differences between groups}

About $51 \%(n=327)$ of respondents in the SI group reported either "very high" or "high" stress, which was significantly higher than the $15 \%(n=745)$ reported by the no-SI group. The SI-Depression group was more than four times as likely as the reference group to report very poor physical health $(34.5 \%$ vs. $8.2 \%)$; the SI-NoDepression group was similar ( $\mathrm{n}=166,31.6 \%)$. In contrast, just $11.5 \%(\mathrm{n}=35)$ of the NoSI-Depression participants considered their physical health to be very poor. About half of each subgroup reported having received no psychological counseling.

\section{The association of EQ-5D, depression, and self-rated physical health with SI}

Table 3 shows the analysis results of the four predictors in the adjusted multiple logistic regression model. Self-control, anxiety/depression of EQ-5D, self-rated physical health, and depression scores showed significant association with SI ( $p<$ 0.0001). The effects of age, gender, educational level, monthly income, marital status, and financial concerns were controlled for in the final model. Figure 1 illustrates how strongly associated the EQ-5D responses were with having SI ("some" versus "severe" problems). The respondents who reported "severe" problems had twice the risk of SI as those who reported "some" problems. The highest odds ratio was found for EQ-5D anxiety/depression $(\mathrm{OR}=9.3, \mathrm{CI}=6.07-14.35)$.

\section{DISCUSSION}

This study found that older adults with SI had significantly lower HRQoL than those without SI. This was demonstrated by the higher proportions of respondents with SI who report- 
ed problems on all five EQ-5D dimensions compared with the no-SI group. The differences in self-control and anxiety/depression were particularly large, with HRQoL being significantly lower on these dimensions among the respondents with SI.
About $11.5 \%$ of the sample of older Koreans reported SI, which was more than twice the prevalence found in studies of community-dwelling older adults in the United States (5.4\%), ${ }^{41}$ Japan (5.6\%), ${ }^{42}$ or Australia (4.5\%). ${ }^{16}$ However, our result was

Table 2. Differences in EQ-5D, psychological factors, and self-rated health by subgroup

\begin{tabular}{|c|c|c|c|c|c|}
\hline \multirow[b]{2}{*}{ Variable } & \multicolumn{2}{|c|}{ Suicidal ideation } & \multicolumn{2}{|c|}{ No suicidal ideation } & \multirow[b]{2}{*}{ p-value } \\
\hline & $\begin{array}{c}\text { Depression } \\
(\mathrm{N}=128,2.3 \%)\end{array}$ & $\begin{array}{l}\text { No depression } \\
(\mathrm{N}=512,9.1 \%)\end{array}$ & $\begin{array}{c}\text { Depression } \\
(\mathrm{N}=291,5.2 \%)\end{array}$ & $\begin{array}{c}\text { No depression } \\
(\mathrm{N}=4,673,83.3 \%)\end{array}$ & \\
\hline \multicolumn{6}{|l|}{ EQ-5D } \\
\hline Physical activity & & & & & $<0.0001$ \\
\hline No problems & $37(27.8)$ & $188(39.9)$ & $158(54.0)$ & $2,986(63.4)$ & \\
\hline Problems & $91(72.2)$ & $324(60.1)$ & $133(46.0)$ & $1,687(36.6)$ & \\
\hline Self-control & & & & & $<0.0001$ \\
\hline No problems & $85(65.9)$ & $368(72.7)$ & $232(79.5)$ & 4,204 (89.9) & \\
\hline Problems & $43(34.1)$ & $144(27.3)$ & $59(20.5)$ & $469(10.1)$ & \\
\hline Daily activity & & & & & $<0.0001$ \\
\hline No problems & $54(36.6)$ & $281(57.3)$ & $195(64.6)$ & $3,707(78.6)$ & \\
\hline Problems & $74(55.4)$ & $231(42.7)$ & $96(35.4)$ & $966(21.4)$ & \\
\hline Pain & & & & & $<0.0001$ \\
\hline No problems & $38(28.5)$ & $190(37.4)$ & $143(44.4)$ & $3,029(64.6)$ & \\
\hline Problems & $90(71.5)$ & $322(62.6)$ & $148(55.6$ & $1,644(35.4)$ & \\
\hline Anxiety/depression & & & & & $<0.0001$ \\
\hline No problems & $34(29.9)$ & $271(52.4)$ & $178(59.7)$ & $4,030(86.2)$ & \\
\hline Problems & $94(70.1)$ & $241(47.6)$ & $133(40.3)$ & $643(13.8)$ & \\
\hline EQ-5D index & & & & & $<0.0001$ \\
\hline 1.0 & $10(8.1)$ & $92(17.5)$ & $78(24.6)$ & $2,305(49.1)$ & \\
\hline$\leq 0.9$ to $<1$ & $10(6.2)$ & $45(10.9)$ & $42(15.4)$ & $446(9.2)$ & \\
\hline$\leq 0.8$ to $<0.9$ & $21(16.9)$ & $106(21.0)$ & $60(19.4)$ & $959(20.7)$ & \\
\hline$\leq 0.7$ to $<0.8$ & $31(23.9)$ & $107(21.8)$ & $63(22.6)$ & $554(11.9)$ & \\
\hline$<0.7$ & $56(44.9)$ & $162(28.8)$ & $48(18.0)$ & $409(9.0)$ & \\
\hline EQ-5D index (mean) & 0.7 & 0.7 & 0.8 & 0.9 & \\
\hline Self-rated stress & & & & & $<0.0001$ \\
\hline Very high & $32(22.7)$ & $72(13.7)$ & $13(5.4)$ & $104(2.3)$ & \\
\hline High & $39(34.3)$ & $184(37.5)$ & $61(19.2)$ & $567(12.2)$ & \\
\hline Moderate & $46(32.9)$ & $186(35.9)$ & $160(55.1)$ & $2,324(49.5)$ & \\
\hline Minor & $11(10.1)$ & $70(12.9)$ & $57(20.3)$ & $1,678(36.0)$ & \\
\hline Self-rated health & & & & & $<0.0001$ \\
\hline Very good & $2(3.0)$ & $8(1.5)$ & $3(1.3)$ & $216(4.9)$ & \\
\hline Good & $11(8.6)$ & $44(8.0$ & $25(8.4)$ & $864(18.1)$ & \\
\hline Moderate & $22(12.9)$ & $148(33.4)$ & $133(44.8)$ & $2,279(48.1)$ & \\
\hline Poor & $50(41.0)$ & $146(25.6)$ & $95(34.0)$ & $943(20.8)$ & \\
\hline Very poor & $43(34.5)$ & $166(31.6)$ & $35(11.5)$ & $371(8.2)$ & \\
\hline Psychological counseling & & & & & $<0.0001$ \\
\hline Yes & $33(25.8)$ & $16(3.1)$ & $49(16.8)$ & $31(1.0)$ & \\
\hline No & $69(54.0)$ & $306(59.8)$ & $138(47.4)$ & $2,555(54.7)$ & \\
\hline
\end{tabular}


Table 3. Adjusted odds ratios* of health-related quality of life (EQ5D) dimensions, physical health, and psychological health as predictors of suicidal ideation $(\mathrm{N}=5,604)$

\begin{tabular}{lcc}
\hline \multirow{2}{*}{ Predictors } & \multicolumn{2}{c}{ Estimates } \\
\cline { 2 - 3 } & Odds ratio $95 \%$ confidence interval \\
\hline EQ-5D & 1.08 & $0.82-1.43$ \\
$\quad$ Physical activity & 1.42 & $1.02-1.96$ \\
Self-control & 1.09 & $0.81-1.45$ \\
Daily activity & 1.17 & $0.88-1.54$ \\
Pain & 2.32 & $1.79-3.02$ \\
Anxiety/depression & & \\
Physical factor & 1.36 & $1.20-1.55$ \\
$\quad$ Self-rated physical health & & \\
Psychological factors & 2.07 & $1.50-2.97$ \\
$\quad$ Depression & 0.57 & $0.47-0.68$ \\
Self-rated stress & 0.97 & $0.93-1.01$ \\
Psychological counseling &
\end{tabular}

*odds ratio adjusted for age, gender, educational level, monthly income, marital status, and financial condition

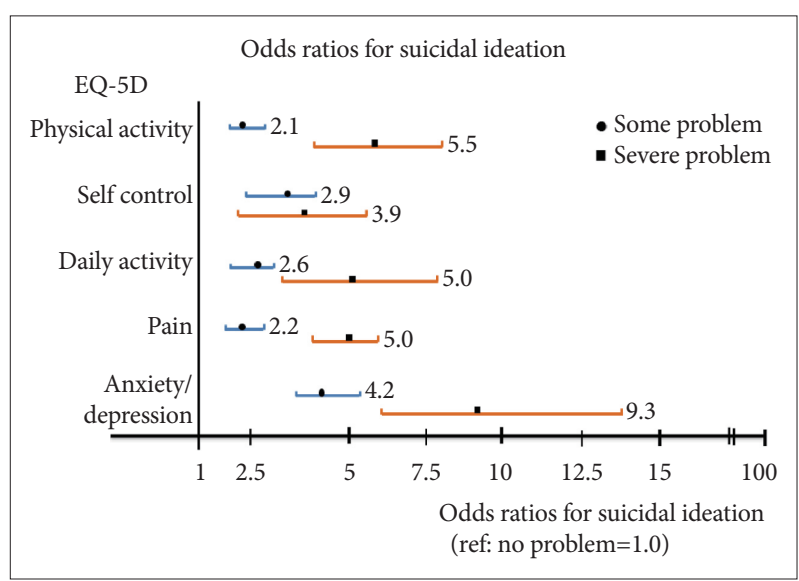

Figure 1. Odds ratios of suicidal ideation for the five EQ-5D dimensions of health-related quality of life among older Koreans. Logistic regression was performed after adjusting for age, gender, monthly income, educational level, marital status, and financial condition.

lower than the $14.7 \%$ incidence of SI observed in a sample of older Korean Americans, ${ }^{43}$ and the $14.5 \%$ incidence of SI among older adults in a rural Chinese community. ${ }^{14}$ Previous studies have found that some socio-demographic characteristics were significantly associated with SI, which was supported by our findings. We found that SI was more likely among females, ${ }^{42}$ those with lower income ${ }^{29,32,42}$ and those who had lower education levels, ${ }^{29}$ which are known contributors to SI among older adults. We focused on the fact that physical and psychological health can be particularly vulnerable among the older adults who were targeted in this study; ${ }^{24}$ thus, we aimed to identify the association of SI and HRQoL which makes it possible to identify both self-rated physical and psychological health level.
To the best of our knowledge, this is the first study to analyze the association of SI and each dimension of EQ-5D. This study found significant associations between each dimension of EQ5D and SI. Therefore, the response results of EQ-5D need to be considered as significant predictors of SI.

\section{A variety of factors associated with SI}

The current study found that in the SI group, the proportion of respondents without depression was almost four times as high as the proportion of those with depression, which addresses the second aim of our study. The main finding of this study was that only 20 percent of older Korean adults were diagnosed with depression in the SI group, which is an interesting result. However, the following limitations need to be considered. First, this number was based on an interview about whether participants were diagnosed with depression by clinicians, and it was not possible to identify how the depression diagnosis was made or whether it was diagnosed by psychiatrists/psychologists or not. Second, there is the potential that the symptoms or characteristics of depression were not clearly revealed through clinical interviews even though depression had been diagnosed by psychiatrists/psychologists in the hospital. In addition, respondents may not have recognized a mental disease such as depression if it was acquired as part of a somatization disorder.

According to the results of a white paper on suicide prevention that was released by the Ministry of Health and Welfare and the Korea Suicide Prevention Center, ${ }^{2}$ the primary reason for older Korean adults to report SI was financial concerns (27.7\%), followed by physical problems (27.6\%). One study found that about $25 \%$ of individuals with high levels of stress reported SI, and high levels of stress led to impaired physical functioning and an increased likelihood of SI. ${ }^{16}$ Our results were similar to these findings, as we found that respondents who rated their physical health as "very poor" and those who reported "very high" stress levels had much higher rates of SI than those with better self-rated health and lower stress levels, respectively. As the main findings of our study, self-control, anxiety/depression of EQ-5D and self-rated physical health were significantly associated with SI when adjusting for age, gender, education level, monthly income, marital status, and financial condition.

\section{Implications of group comparisons}

We considered different severity levels in each of the five EQ-5D dimensions, as well as the proportion of individuals with SI reporting "very much" stress/distress and "very poor" self-rated health was overwhelmingly higher than those in the no-SI group. Individuals with SI were consistently more likely to report problems in all five EQ-5D dimensions and have a lower-level EQ-5D index as well as lower mean values than those without SI. Based on these results, we believe that the 
EQ-5D would be a useful screening tool for SI among older adults. In addition, the proportion of individuals with SI reporting "very high" stress and "very poor" self-rated health was overwhelmingly higher than those in the no-SI group.

Respondents in the SI-NoDepression group were not likely to be involved in psychological counseling (3.1\%). It is reasonable that people without psychological symptoms, such as depressive symptoms, do not seek psychological counseling or treatment; in addition, a previous study reported that many individuals with SI did not receive any type of intervention or treatment. ${ }^{44}$

\section{Strengths and limitations}

Our study makes some important contributions. First, it is the first study to analyze the separate associations of the five EQ-5D dimensions with SI among older Koreans. Furthermore, we investigated the differences in SI risk based on the severity of problems (i.e., "some" or "severe" problems) in the five dimensions. Second, we used data collected using proper weighted nationwide sampling, which provided national estimations for older Koreans. Therefore, the results of this study could be generalized to older adults aged over 65 years living in Korean communities.

One limitation of this study is its cross-sectional design, which precludes causal inferences about the relationship between HRQoL and SI. Nevertheless, our findings were in line with previous studies that found negative relationships between quality of life and SI. ${ }^{9,28,29,40} \mathrm{~A}$ second limitation is that most measures were based on self-report data, which might involve recall bias.

In conclusion, we systematically investigated physical and psychological factors as well as the five dimensions of the EQ$5 \mathrm{D}$, which have been shown to play an important role in SI among Korean older adults. Among the investigated factors, self-control and anxiety/depression of the EQ-5D, self-rated physical health, and depression were significant predictors of SI, which was consistent with previous studies. ${ }^{45}$ Therefore, effective ways to screen for and treat SI should not be limited to assessing and dealing with psychological problems, such as depression. In addition, the EQ-5D might be a useful screening tool to detect SI among older Korean adults, because it would be possible to find out how severely physical and psychological health were reported in each of the five dimensions of EQ-5D. Thus, depression screening as well as using EQ-5D, to detect SI could contribute to the reduced likelihood that a person progresses toward suicidal plans or suicidal attempts. In a future study, it would be helpful to identify the continued correlations between five dimensions of EQ-5D and SI with longitudinal analysis using cohort data of the community. Thus, it could provide valid evidence that the EQ-5D could be used as a screening tool for suicide prevention.

\section{Supplementary Materials}

The online-only Data Supplement is available with this article at https://doi.org/10.30773/pi.2020.0159.

\section{Acknowledgments}

We are grateful to the Korea Centers for Disease Control and Prevention and the Ministry of Health and Welfare for providing us with the nationally representative cross-sectional survey data used in this study.

\section{Conflicts of Interest}

The authors have no potential conflicts of interest to disclose.

\section{Author Contributions}

Conceptualization: Jinyoung Jang, Sukil Kim. Data curation: Jinyoung Jang, Hyun-Sung Jung. Formal analysis: Jinyoung Jang, Hyun-Sung Jung. Funding acquisition: Jinyoung Jang. Investigation: Jinyoung Jang, HyunSung Jung, Jumee Wang. Methodology: Jinyoung Jang, Sukil Kim. Project administration: Jinyoung Jang, Jumee Wang. Resources: Jinyoung Jang. Visualization: Jinyoung Jang, Jumee Wang. Writing_original draft: Jinyoung Jang. Writing_review \& editing: all authors.

\section{ORCID iDs}

Jinyoung Jang https://orcid.org/0000-0002-2744-6374

Hyun-Sung Jung https://orcid.org/0000-0002-7769-961X

Jumee Wang https://orcid.org/0000-0002-5125-5949

Sukil Kim https://orcid.org/0000-0001-9730-9845

\section{REFERENCES}

1. OECD. Suicide rate. 2017. Available at: https://data.oecd.org/healthstat/suicide-rates.htm. Accessed October 20, 2019.

2. MOHW. White Paper on Suicide Prevention. Seoul: Ministry of Health \& Welfare Korea Suicide Prevention center; 2019;29.

3. Blazer DG. Depression in late life: review and commentary. J Gerontol A Biol Sci Med Sci 2003;58:249-265.

4. Brown GK, Beck AT, Steer RA, Grisham JR. Risk factors for suicide in psychiatric outpatients: a 20-year prospective study. J Consult Clin Psychol 2000;68:371-377.

5. Spicer RS, Miller TR. Suicide acts in 8 states: incidence and case fatality rates by demographics and method. Am J Public Health 2000;90:18851891.

6. Hawley CJ, James DV, Birkett PL, Baldwin DS, de Ruiter MJ, Priest RG. Suicidal ideation as a presenting complaint. Associated diagnoses and characteristics in a casualty population. Br J Psychiatry 1991;159:232238.

7. Dong Y, Huang F, Hu G, Liu Y, Zheng R, Zhang Q, et al. The prevalence of suicidal ideation among the elderly in China: a meta-analysis of 11 cross-sectional studies. Compr Psychiatry 2014;55:1100-1105.

8. Jorm AF, Henderson AS, Scott R, Korten AE, Christensen H, Mackinnon AJ. Factors associated with the wish to die in elderly people. Age Ageing 1995;24:389-392.

9. Joshi P, Song HB, Lee SA. Association of chronic disease prevalence and quality of life with suicide-related ideation and suicide attempt among Korean adults. Indian J Psychiatry 2017;59:352-358.

10. Scocco P, Meneghel G, Caon F, Dello Buono M, De Leo D. Death ideation and its correlates: survey of an over-65-year-old population. J Nerv Ment Dis 2001;189:210-218.

11. Skoog I, Aevarsson O, Beskow J, Larsson L, Palsson S, Waern M, et al. Suicidal feelings in a population sample of nondemented 85-year-olds. Am J Psychiatry 1996;153:1015-1020.

12. Yip PS, Chi I, Chiu H, Chi Wai K, Conwell Y, Caine E. A prevalence 
study of suicide ideation among older adults in Hong Kong SAR. Int J Geriatr Psychiatry 2003;18:1056-1062.

13. Barnow S, Linden M, Freyberger HJ. The relation between suicidal feelings and mental disorders in the elderly: results from the Berlin Aging Study (BASE). Psychol Med 2004;34:741-746.

14. Xu H, Qin L, Wang J, Zhou L, Luo D, Hu M, et al. A cross-sectional study on risk factors and their interactions with suicidal ideation among the elderly in rural communities of Hunan, China. BMJ Open 2016;6: e010914.

15. Dutta R, Ball HA, Siribaddana SH, Sumathipala A, Samaraweera S, McGuffin P, et al. Genetic and other risk factors for suicidal ideation and the relationship with depression. Psychol Med 2017;47:2438-2449.

16. Handley TE, Hiles SA, Inder KJ, Kay-Lambkin FJ, Kelly BJ, Lewin TJ, et al. Predictors of suicidal ideation in older people: a decision tree analysis. Am J Geriatr Psychiatry 2014;22:1325-1335.

17. Rurup ML, Deeg DJ, Poppelaars JL, Kerkhof AJ, Onwuteaka-Philipsen $\mathrm{BD}$. Wishes to die in older people: a quantitative study of prevalence and associated factors. Crisis 2011;32:194-203.

18. Fassberg MM, van Orden KA, Duberstein P, Erlangsen A, Lapierre S, Bodner E, et al. A systematic review of social factors and suicidal behavior in older adulthood. Int J Environ Res Public Health 2012;9:722745 .

19. Kissane M, McLaren S. Sense of belonging as a predictor of reasons for living in older adults. Death Stud 2006;30:243-258.

20. Saias T, Beck F, Bodard J, Guignard R, du Roscoat E. Social participation, social environment and death ideations in later life. PLoS One 2012;7:e46723.

21. Ladwig KH, Klupsch D, Ruf E, Meisinger C, Baumert J, Erazo N, et al. Sex- and age-related increase in prevalence rates of death wishes and suicidal ideation in the community: results from the KORA-F3 Augsburg Study with 3,154 men and women, 35 to 84 years of age. Psychiatry Res 2008;161:248-252.

22. Peter T, Roberts LW, Buzdugan R. Suicidal ideation among Canadian youth: a multivariate analysis. Arch Suicide Res 2008;12:263-275.

23. Vasiliadis HM, Gagne S, Preville M. Gender differences in determinants of suicidal ideation in French-speaking community living elderly in Canada. Int Psychogeriatr 2012;24:2019-2026.

24. Policy Committee of Suicide Prevention. National Action Plan for Suicide Prevention, Current Situation and Future Plan. Seoul: Office of The Prime Minister; 2019.

25. Goldney RD. Finland's contribution to suicide prevention. Crisis 2004; 25:86-87.

26. U.S. Department of Health \& Human Services. Does depression increase the risk for suicide? 2014. Available at: https://www.hhs.gov/answers/ mental-health-and-substance-abuse/does-depression-increase-riskof-suicide/index.html. Accessed February 14, 2020.

27. Joo J, Hwang S, Gallo JJ. Death ideation and suicidal ideation in a community sample who do not meet criteria for major depression. Crisis 2016;37:161-165.

28. Fairweather-Schmidt AK, Batterham PJ, Butterworth P, Nada-Raja S. The impact of suicidality on health-related quality of life: a latent growth curve analysis of community-based data. J Affect Disord 2016;203:14-
21.

29. Kim JH, Kwon JW. The impact of health-related quality of life on suicidal ideation and suicide attempts among Korean older adults. J Gerontol Nurs 2012;38:48-59.

30. Mitchell AM, Sakraida TJ, Kim Y, Bullian L, Chiappetta L. Depression, anxiety and quality of life in suicide survivors: a comparison of close and distant relationships. Arch Psychiatr Nurs 2009;23:2-10.

31. Yang B, Lester D. Suicide as an indicator of quality of life: apparent conflict between microeconomic and macroeconomic approaches. Percept Mot Skills 2001;93:95-96.

32. Ponte C, Almeida V, Fernandes L. Suicidal ideation, depression and quality of life in the elderly: study in a gerontopsychiatric consultation. Span J Psychol 2014;17:E14.

33. Balestroni G, Bertolotti G. [EuroQol-5D (EQ-5D): an instrument for measuring quality of life]. Monaldi Arch Chest Dis 2012;78:155-159.

34. Garratt A, Schmidt L, Mackintosh A, Fitzpatrick R. Quality of life measurement: bibliographic study of patient assessed health outcome measures. BMJ 2002;324:1417.

35. Kim MH, Cho YS, Uhm WS, Kim S, Bae SC. Cross-cultural adaptation and validation of the Korean version of the EQ-5D in patients with rheumatic diseases. Qual Life Res 2005;14:1401-1406.

36. Kim SH, Hwang JS, Kim TW, Hong YS, Jo MW. Validity and reliability of the EQ-5D for cancer patients in Korea. Support Care Cancer 2012; 20:3155-3160.

37. Kim SH, Jo MW, Lee JW, Lee HJ, Kim JK. Validity and reliability of EQ-5D-3L for breast cancer patients in Korea. Health Qual Life Outcomes 2015;13:203.

38. Lee YK, Nam HS, Chuang LH, Kim KY, Yang HK, Kwon IS, et al. South Korean time trade-off values for EQ-5D health states: modeling with observed values for 101 health states. Value Health 2009;12:11871193.

39. Jung KI, Park CK. Mental health status and quality of life in undiagnosed glaucoma patients: a nationwide population-based study. Medicine (Baltimore) 2016;95:e3523.

40. Min JY, Min KB. Suicide behaviors and health-related quality of life: results from the Korean community health survey of 393,073 adults. Afr J Psychiatry 2015;18:214.

41. Barnow S, Linden M. Epidemiology and psychiatric morbidity of suicidal ideation among the elderly. Crisis 2000;21:171-180.

42. Awata S, Seki T, Koizumi Y, Sato S, Hozawa A, Omori K, et al. Factors associated with suicidal ideation in an elderly urban Japanese population: a community-based, cross-sectional study. Psychiatry Clin Neurosci 2005;59:327-336.

43. Na PJ, Kim KB, Lee-Tauler SY, Han HR, Kim MT, Lee HB. Predictors of suicidal ideation in Korean American older adults: analysis of the Memory and Aging Study of Koreans (MASK). Int J Geriatr Psychiatry 2017;32:1272-1279.

44. Bruffaerts R, Demyttenaere K, Hwang I, Chiu WT, Sampson N, Kessler RC, et al. Treatment of suicidal people around the world. Br J Psychiatry 2011;199:64-70.

45. Deuter K, Procter N, Evans D, Jaworski K. Suicide in older people: Revisioning new approaches. Int J Ment Health Nurs 2016;25:144-150. 


\section{SUPPLEMENTARY MATERIAL}

\section{EQ-5D index formula}

$\mathrm{y}=1-\left(0.050+0.096 * \mathrm{M} 2+0.418^{*} \mathrm{M} 3+0.046 * \mathrm{SC} 2+0.136 * \mathrm{SC} 3+0.051 * \mathrm{UA} 2+0.208 * \mathrm{UA} 3+0.037 * \mathrm{PD} 2+0.151 * \mathrm{PD} 3+0.043 * \mathrm{AD} 2+0.15\right.$ $\left.8^{*} \mathrm{AD} 3+0.050^{*} \mathrm{~N} 3\right)$

$\begin{array}{ll}\text { M2 } & \text { Physical activity "Level 2" }=1 \text {; otherwise }=0 \\ \text { M3 } & \text { Physical activity "Level 3" }=1 \text {; otherwise }=0 \\ \text { SC2 } & \text { Self-control "Level 2" }=1 \text {; otherwise }=0 \\ \text { SC3 } & \text { Self-control "Level } 3 \text { " }=1 \text {; otherwise }=0 \\ \text { UA2 } & \text { Daily activity "Level 2" }=1 \text {; otherwise }=0 \\ \text { UA3 } & \text { Daily activity "Level 3" }=1 \text {; otherwise }=0 \\ \text { PD2 } & \text { Pain "Level 2" }=1 \text {; otherwise }=0 \\ \text { PD3 } & \text { Pain "Level 3" }=1 \text {; otherwise }=0 \\ \text { AD2 } & \text { Anxiety/depression "Level 2" }=1 \text {; otherwise }=0 \\ \text { AD3 } & \text { Anxiety/depression "Level 3" }=1 \text {; otherwise }=0 \\ \text { N3 } & \text { If there is at least one dimension at "Level 3" }=1 \text {; otherwise }=0\end{array}$

In the EQ-5D index formula, numbers 2 and 3 indicate the level of severity in the five dimensions of the EQ-5D ("some problems" and "severe problems," respectively). N3 is set at 1 or 0 if at least one dimension at Level 3 (severe problems) is 1; otherwise, $\mathrm{N} 3$ is set at 0 . 